\title{
Autoimmune hepatitis as an overlap of secondary antiphospholipid syndrome
}

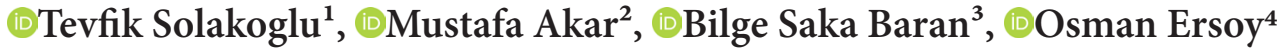 \\ ${ }^{1}$ Tekirdag Namik Kemal University, Faculty of Medicine, Department of Gastroenterology, Tekirdağ, Turkey \\ ${ }^{2}$ Health Sciences University, Bursa Yüksek İhtisas Training and Research Hospital, Department of Gastroenterology, Bursa, Turkey \\ ${ }^{3}$ Karadeniz Ereğli State Hospital, Department of Pathology, Zonguldak, Turkey \\ ${ }^{4}$ Yildirim Beyazit University, Faculty of Medicine, Department of Gastroenterology, Ankara, Turkey
}

Cite this article as: Solakoğlu T, Akar M, Saka Baran B, Ersoy O. Autoimmune hepatitis as an overlap of secondary antiphospholipid syndrome. J Health Sci Med 2021; 4(3): 400-401.

\section{Dear Editor,}

Antiphospholipid syndrome (APS) is a systemic autoimmune disease characterized by the presence of antiphospholipid autoantibodies [anticardiolipin antibodies $(\mathrm{aCL})$, lupus anticoagulant antibodies (aLA), and antibodies to $\beta 2$-glycoprotein I (anti-ß2 GPI)] (1). Autoimmune hepatitis (AIH), is a chronic progressive liver disease with undefined etiology. It is mainly seen in female patients and identified by hypergammaglobulinaemia, circulating autoantibodies, and a recovery after immunosuppression (2). So far, there was a limited number of case reports including the association between $\mathrm{AIH}$ and the presence of antiphospholipid antibodies (aPL) and/or APS (2). We present a female patient manifested by $\mathrm{AIH}$ associated with systemic lupus erythematosus (SLE) related APS.

A 49-year-old female patient previously diagnosed with secondary APS (using revised Sapporo APS classification criteria) associated with SLE was admitted to the hospital with elevation levels of aminotransferase for longer than 6 months. In her history, two pregnancy loss and deep vein thrombosis was detected. Antinuclear antibody (ANA $=1 / 100)$, Anti-double stranded DNA(anti-ds DNA), aCLIgM/IgGandaPLIgM/IgGwereallpositive.Laboratory findings were as follows; Aspartate aminotransferase (AST): $59 \mathrm{U} / \mathrm{L}$ (0-40), alanine aminotransferase (ALT): $74 \mathrm{U} / \mathrm{L}$ (0-41), alkaline phosphatase (ALP):49 IU/L (40130), ferritin: $20 \mathrm{ng} / \mathrm{dl}$ (13-150), ceruloplasmin: $32 \mathrm{mg} /$ dl (20-60). Serum Ig G level was elevated 3 times the upper limit of normal and anti-smooth muscle antibodies $(A S M A=1 / 100)$ was positive. Viral serology for hepatitis $\mathrm{A}, \mathrm{B}, \mathrm{C}$ virus, antimitochondrial antibodies ( AMA-M2), liver kidney microsomal type 1 antibody (LKM-1), rheumatoid factor (RF) and brucella agglutination test were also negative. Thyroid function tests were normal.
There was no history of drugs, traditional supplements and alcohol consumption. In hepatobiliary ultrasound; liver parenchymal echogenicity was heterogeneous. On the liver histopathology (Figure 1); in all of the portal areas, mixed type of inflammation were observed accompanied by moderate neutrophil leukocytes (Figure 1A-C). The basic structure of liver were preserved except mild fibrous expansion of the portal areas (Figure 1D,E). There were proliferation in the ductus closed to portoparenchymal junction and inflammation of the bile ducts was not observed (Figure 1F). In some of portoparenchymal junctions piecemal activity were present. Although all these results were not specific for AIH, it was supported by the revised original Diagnostic Scoring System of the International Autoimmune Hepatitis Group (IAIHG). Pre-treatment revised original IAIHG score of the patient was 18 . Thus, prednisolone $60 \mathrm{mg} /$ day was started and tapered to the optimal dose. In the first month of the treatment with prednisolone, liver enzymes returned to normal range. Post-treatment revised original IAIHG score was 20.

SLE-associated hepatitis (Lupus hepatitis) and AIH are two different conditions (3). Hueber et al. (4) reported the first case of AIH occurred after the diagnosis of primary APS in the literature. Ambrosino et al. (5) reported that the presence of antiphospholipid antibodies in $\mathrm{AIH}$ was frequently detected but $\mathrm{AIH}$ is rarely reported in combination with APS. Until now case report about autoimmune hepatitis after the diagnosis of SLE related APS has not been published yet in the English literature.

To our best knowledge, the present case is the first case of AIH as an overlap of SLE related APS in the English literature. In conclusion, AIH should be kept in mind in APS patients with elevated liver enzymes. 


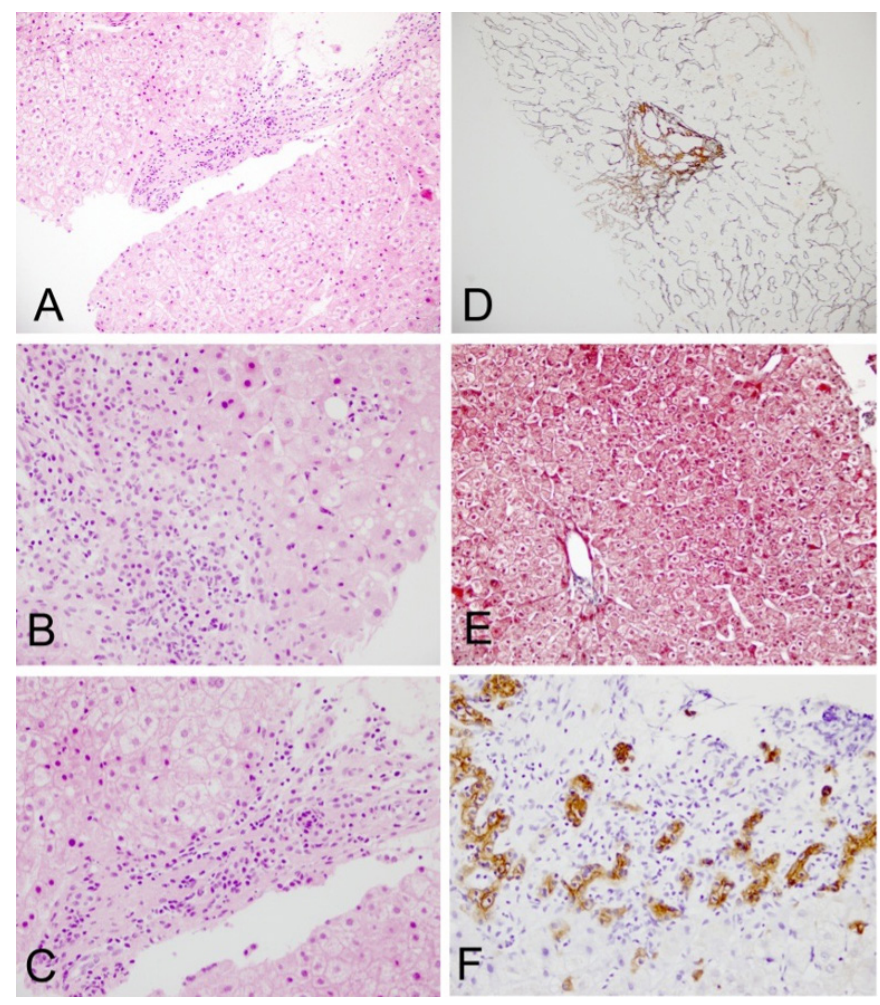

Figure 1. A-C: In all of the portal areas, mixed type of inflammation were observed accompanied by moderate neutrophil leukocytes (Hematoxylin and eosin, 100x ve 200x), D: Mild fibrous expansion of the portal areas (Reticulin, 40x), E: The basic structure of liver were preserved. There were no significant changes in the vessels and central veins (Trichrome, 100x). F: There were proliferation in the ductus closed to porto-parenchymal junction. (CK7, 200x)

\section{ETHICAL DECLARATIONS}

Referee Evaluation Process: Externally peer-reviewed.

Conflict of Interest Statement: The authors have no conflicts of interest to declare.

Financial Disclosure: The authors declared that this study has received no financial support.

Author Contributions: All of the authors declare that they have all participated in the design, execution, and analysis of the paper, and that they have approved the final version.

\section{REFERENCES}

1. Levine JS, Branch DW, Rauch J. The antiphospholipid syndrome. N Engl J Med 2002; 346: 752-63.

2. Uthman I, Khamashta M. The abdominal manifestations of the antiphospholipid syndrome. Rheumatology 2007; 46: 1641-7.

3. Youssef WI, Tavill AS. Connective tissue diseases and the liver. J Clin Gastroenterol 2002; 35: 345-9.

4. Hueber AJ, Boxberger F, Ganslmayer M, Hahn EG. Antiphospholipid syndrome in combination with autoimmune hepatitis. Eur J Gastroenterol Hepatol 2005; 17: 241-3.

5. Ambrosino P, Lupoli R, Spadarella G, et al. Autoimmune liver diseases and antiphospholipid antibodies positivity: a metaanalysis of literature studies. J Gastrointestin Liver Dis. 2015; 24: 25-34. 